\title{
INTRODUCTION: BACK TO RELATIONS IN THEMSELVES
}

Elżbieta Hałas

University of Warsaw

Pierpaolo Donati

University of Bologna

The category of relation is obviously nothing new in social theory; in a sense, it has been taken for granted for a long time. However, refocusing on social relations, on their constitution and effects, leads to a new way of observing, describing, understanding and explaining social phenomena as relational facts. This novel outlook includes the concept of the human being as homo relatus, as articulated in The Relational Subject, co-authored by Pierpaolo Donati and Margaret S. Archer. The special issue The Relational Turn in Sociology: Implications for the Study of Society, Culture, and Persons serves as an agora for the exposition of the main relational ideas, crucial theses, and concomitant debates.

It is necessary to justify the use of the expression "relational turn." Obviously, the term "turn" is characteristic for the postmodernist poetics that is replacing the logic of scientific theorizing. Therefore, it must be stipulated that no aspiration to yet another "postmodern turn" comes into play here. On the contrary, the relational turn is associated with a critical standpoint towards postmodernism, an opaque form of cultural cognition which proves subversive in regard to rational scientific knowledge.

Furthermore, the relational turn we have in mind encourages a return to scientific activities rooted in ontological investigations of social and cultural realities in order to deepen the understanding of those realities and to increase our ability to manage the ongoing contemporary changes of the globalized world. This applies both to advancing theories and to building research programmes, as well as to designing their practical applications through relational lenses. Ontological investigations are accompanied by 
a honing of relational epistemological consciousness as the background for a new relational theory of society. In other words, metaphorically speaking, the new relational sociology does not participate in the spiral of continually evoked postmodern turns, either linguistic or performative, or any other turns of the postmodern kind, which ultimately lead to a kind of vertigo hampering development of the social and cultural sciences. The relational turn does not ally with the turn understood as a praxis that radicalizes the erosion of all cultural traditions; on the contrary, it focuses on tracking the morphogenetic processes that shape the contours of the after-modern.

Relational sociology overcomes the postmodernist vision to study the emergence of the after-modern in various configurations and the inception of morphogenic society through human agency, and in doing so, highlights the challenge of re-articulating social relations as a task of central importance.

All this does not mean that the collocation "relational turn" in the title of this special issue is being used only to draw attention and to provoke those scholars who rightly point out that the concept of a "turn" has undergone troubling inflation of meaning since it became popularized by such authors as Richard Rorty or Clifford Geertz, and adopted by Jeffrey C. Alexander and others who speak of a cultural turn or other turns.

However, our use of the expression "relational turn" is justified not only by the fact that Pierpaolo Donati, the founder of relational sociology, uses it purposefully (along with such categories as "approach," "paradigm," and "theory," all precisely specified), but also by the actual scope of this endeavour.

Significantly, although the current momentum of relational thinking is particularly impressive and important, in fact the itinerary to the "relational turn" we currently face has been a very long one, and various relational turning points have appeared on this route from antiquity until modernity, when the sciences emancipated themselves from metaphysical thinking in terms of substances. Subsequently, on the shorter sociological stretch of this road, true relational turns have already been executed by Georg Simmel, Alfred Vierkandt, Florian Znaniecki and others who discovered that the relation is the fundamental category of social thought.

"Turn" is obviously a much more ambiguous term than "paradigm," a notion successfully introduced and discussed by Thomas Kuhn, which has subsequently gained many proponents and many critics. "Turn" refers to a gradual transformation of the field of scientific theories, rather than a scientific revolution. Several characteristic features of a "turn" observed 
by, among others, Doris Bachmann-Medick in her book on cultural turns, appear to correspond well with significant traits of the relational turn. We are referring here to what Gaston Bachelard called an epistemological rupture, which is brought about by introducing an innovative vocabulary that opens up new analytic perspectives. Subsequently, an attempt to reconstruct the scientific domains of knowledge under conditions of their growing fragmentation takes place, followed by the introduction of a novel perspective that shows existing knowledge in a new light and draws attention to hitherto ignored aspects of ongoing processes. The final step consists of moving on from the research object to the category of analysis. Thus, the relational turn means not only focusing on social relations as the subject matter; it also involves elaborating new and properly relational categories of analysis, such as the concepts of relational reflexivity and relational goods (or relational evils).

The characteristics listed above are remarkable features of a genuine new intellectual movement that enters into debates and polemics, particularly as regards various ways of understanding relations and relationality in themselves. Pierpaolo Donati argues that most existing approaches, both historical and modern, that take relationality into account cannot be considered relational sociology in a true sense. They are either not explicit enough or mistaken in many aspects, and thus should be regarded merely as relationistic. The best example is Mustafa Emirbayer's Manifesto for a Relational Sociology, which reduces social relations to mere "transactions," without focusing properly on the internal dynamics and structures of relations as such.

"Relational sociology" denotes the approach initiated in Italy in the 1980s as described in Pierpaolo Donati's Relational Sociology: A New Paradigm for the Social Sciences. The multitude of various orientations and standpoints that proliferate under the umbrella of relationality serve, at least in part, as material for reflections presented in some papers contained in this volume, albeit the genuine relational theory of society remains at the core.

It should be mentioned at this point that significant connections exist between the relational movement in a broad sense and network theory. Among the creators of the latter is Harrison C. White from Columbia University, whose work Identity and Control: How Social Formations Emerge is the landmark of the approach now known as the New York School of relational sociology. It is necessary to hasten the discussion about the merits and shortcomings of network theory with regard to relational sociology in a strict sense. These questions are also mentioned in this special issue. 
Symbolic interactionism and social phenomenology, two very important new orientations of the twentieth century, so attractive for the generation of sociologists coming of age in the 1970s, also hold significance for relational sociology, because internal conversation and reflexivity of the self are a crucial part of the relational theory of agency. Questions regarding reflexivity are also discussed in some articles contained in this volume.

As far as the pace of grasping the relational perspective is concerned, one may reflect upon the fact that in the 1980s, despite political obstacles, the interpretative turn was quickly accommodated in Poland. At that time the Internet did not exist yet, and the communist regime limited scholars' opportunities to communicate and exchange ideas with the West. Despite those serious obstacles, the first reception of interpretative approaches in Poland was not delayed. Today, there is no justification for any further postponement of joining new research currents and discussing questions as important as the ones contained in the relational theory of society and the theory of morphogenesis, as well as the cultural version of network theory and their mutual interactions. Incidentally, Polish sociology has a great tradition of theories and research on social and cultural change, based on epistemological and ontological reflection. This includes traditions of relational thinking.

This special issue is the fruit of the first international seminar on relational sociology organized in Poland in September 2016 at the University of Warsaw. Hopefully, our encouragement to take up the relational approach will elicit a response in the sociological milieu and beyond.

It is not the task of the Introduction to carry out a comprehensive discussion summing up all contributions to the special issue. It is neither possible nor necessary to summarize in a few words the complex problems analysed by the contributors. However, some preliminary hints to the readers might prove useful.

Twelve articles revolve around three major topics: pivotal issues of the general relational theory of society and culture, relational theory of the subject, and pertinent contemporary questions about the life-world and civil society. The opening article by Pierpaolo Donati highlights the distinctive features of relational sociology, contrasting them with the limitations of relationist theories. The author argues that to understand the increasing complexity of contemporary societies, it is necessary to perceive the social as relational in a true sense and to adopt the premise that the key to solving the problems of contemporary society can be found in the area of social relations. 
Aleksander Manterys puts the relational realism of Pierpaolo Donati in a larger context of other approaches, as exemplified by Jan A. Fuhse's communicative approach to relations on the backdrop of Harrison C. White's social networks theory, and François Dépelteau's transactional approach stemming from pragmatism. The analysis presents new theoretical riddles and the advantages of the relationalization of fundamental sociological categories. The critical realist relational approach is further explored by asking pertinent theoretical questions. Marta Bucholc investigates the role of language and communicative situations within the relational paradigm, providing a larger context for discussions and polemics from that angle. Elżbieta Hałas, on the other hand, tackles the issue of symbolization within relational sociology while asking about the relational conception of culture. The article exposes the complex nature and central place of culture in relational sociology, and examines the possibilities for introducing a wider notion of cultural reality.

At the volume's core are problems concerning the relational subject. Andrea Maccarini deals with socialization processes and reflexivity in late modernity articulated in morphogenetic terms. He focuses on different identity-building processes and challenges of deep transformations of human reflexivity. Lorenza Gattamorta concentrates on the symbolic Werelation while investigating how subjectivity is formed in the course of interaction with symbols. The problem of social identity presents itself in a new light after the relational turn. Irena Szlachcicowa discusses different concepts of identity within relationally-oriented sociology and compares the narrative and realist approaches. This thematic sequence finds empirical contextualization in the article by Giovanna Rossi, Donatella Bramanti and Stefania G. Meda on the relational sociology approach to active ageing. Focusing on intergenerational relations and other relational networks, the authors explore the ways in which individuals attempt to face ageing actively.

Finally, a number of articles explore interdependencies among the life-world, social system, and civil society. Paolo Terenzi presents the interpretation of everyday life from the perspective of relational sociology, overcoming the dualism between the Marxist perspective of alienation and the phenomenological analysis of meaning production. He searches for a new form of secularism, able to accommodate non-fundamentalist aspects of religious beliefs. Emiliana Mangone examines risk as a dimension of everyday life. She attempts to conceptualize risk following the referential and structural semantics of social relations and the positive or negative 
results of risk, which depend on resources and challenges. Víctor PérezDíaz discusses the development of civil society in the relational context, as exemplified by the case of Spanish citizenry. By investigating civil forms of doing politics, he takes into consideration vast cultural resources and the strategic capacity of human agency to orient itself in a context of growing uncertainty. Finally, Tomasz Zarycki voices a call for the development of a critical sociology of discourse analysis founded upon a relational perspective. He argues that discourse analysis, including Critical Discourse Analysis (CDA), is dependent on power relations. He proposes a reflexive and relational programme based on a sociology of knowledge, inspired by Pierre Bourdieu's "sociology of sociology."

The reader can also become acquainted with the humanistic message carried by relational sociology, thanks to a report from the seminar "Humanism in an After-Modern Society: The Relational Perspective" (Warsaw, March 2017) and comments by Michał Federowicz and Daniel Sobota, Aleksander Manterys and Tadeusz Szawiel. Reviews written by Fabio Ferrucci, Joanna Bielecka-Prus, Elżbieta Hałas, Sławomir Mandes and Mikołaj Pawlak, assessing recent books relevant for the further development of relational theory of society and its applications, complement this special issue.

Breaking away from minimalism, genuine relational sociology attempts to reconstruct a general sociological theory, which is an imperative goal in the age of globalization. The relational theory of morphogenetic social and cultural changes is relevant not only in terms of its analytical and conceptual sophistication, but also because it encompasses a layer of ideas associated with the problems of the common good as a relational good. The emancipatory aspect related to the practical problems of civil society cannot pass unnoticed.

Sociology's task of researching social relations is free from sociologism. As Margaret S. Archer aptly emphasizes, relations with the world can neither be reduced to the social order nor contained within its limits. A particularly significant feature of relational sociology must be accentuated: it liberates itself from inadequate, reductionist models of homo oeconomicus and homo sociologicus by focusing on the human person and his or her relational constitution. 